\title{
Applications of infrared thermogrammetry in thermal engineering
}

(1) Institute of Thermal Energy and Systems Engineering, Technical University Budapest (BME-HRI), H.1521 Budapest, Hungary.

\section{Abstract}

Examples from energy saving, thermotechnology, electrotechnics, agriculture and human biology confirm practical applications of IR-thermogrammetric CAD: examination of emissivity, halogen lamp, wall heating, radiators, venetian blinds, green houses, furnaces, insulations, high-voltage lines, district heating and leakage spots.

\section{Introduction}

In Hungary, the application of the technique of infrared (IR) imagery (IRthermography) dates back to 1972 and since 1977 the symposia on Thermogrammetry summarized the results in this field [1]. In 1987 a new scientific forum was established, the International Conference on Thermogrammetry and Thermal Engineering.

The development of IR-imaging systems and equipment in the past years provides some new opportunities for the quantitative evaluation of IR-pictures (in Hungary by computerized processing since 1985), i.e. a numerical definition of proper accuracy of the temperature distribution on the surface of an object under observation and the computerized processing of IR-picture analysis.

Among multiple industrial applications, some typical examples will be presented here, without an in-depth analysis: examination of emissivity of different materials, halogen lamp. Thermal examination of furnace and steam turbine insulations, high-voltage lines, district heating and leakage spots.

\section{Examination of emissivity of different materials}

In the past years great attention has been paid to studying the emissivity of different materials. The method used in our study was one of the direct comparative type in which the intensity of radiation received by an infrared imaging equipment from the heated specimen was used to determine the normal spectral emissivity. The half of each specimen was coated by different coatings while the other half was uncoated.

The measuring method consists of two consecutive steps. In the first step the IR-imaging equipment, which viewed the specimen at right angles to the surface of the sample, received both the radiation emitted by the specimen and the environmental radiation (e.g. sun or furnace) reflected from it. In the second step, the sample shielded from the environmental radiation, the IR-imaging equipment received only the 
radiation emitted by the non-uniform heated coated and uncoated sides of the specimen. The process took a few seconds and the video recording of the infrared measurements was subsequently evaluated with computerised analysis.

Two examples will be presented here: a high emissivity coating and a low emissivity coating. The high emissivity coating is a silicon carbide based furnace coating, such as Enecoat, increases the surface emissivity of refractories [2], and yield energy savings and more homogeneous thermal effects. The low emissivity coating is a selective sun reflecting coating. From thermal point of view the coating is a double function membrane: it saves energy of wall structures year-round, as it lowers interior temperatures in summer and its low emissivity slows heat loss in winter [4] .

\subsection{High emissivity furnace coating}

The infrared radiation of samples of different insulating materials was examined in electric furnaces (fig. 1). at temperatures ranging from $100^{\circ} \mathrm{C}$ to $1000^{\circ} \mathrm{C}$ (measured by a thermocouple) by heating the sample in the furnace to the desired temperature, and placing a shield (surface temperature 20-40 ${ }^{\circ} \mathrm{C}$ ) around it to screen it from tho furnace so that the radiation of the sample could be accurately measured. The shield was made of white ceramic fibre so that all the effects of reflected energy from the hot environment could be cancelled. The measurement was carried out in a very short time after the shield had been placed in the furnace. This allowed the effects of tho shield on the temperature field to be ignored. The lack of change in the gradients along the perimeter of the sample indicates that this assumption was correct. Figure 2 illustrates the infrared thermal image obtained as a result. A method was worked out to evaluate the temperature field on the surface of the samples and for calculating the emissivity at certain temperatures [3][6]. Connection between the temperature and emissivity ratios is given by the following equation:

$$
\frac{\bar{\epsilon}_{1}}{\bar{\epsilon}_{2}}=\frac{\bar{T}_{2}^{4}}{\bar{T}_{1}^{4}}
$$

Table 1 shows an example of the calculations and also that emissivity of Enecoat at $960^{\circ} \mathrm{C}$ reaches values in the range 0.63 to 0.56 . Spectral normal emissivity of Enecoat (high emissivity furnace coating), chamotte and ceramic fibre against material surface temperature can be seen in fig. 3. In figure 2, two vertical and one horizontal lines across the thermogram mark the cross-sections on the sample, for which temperature distribution was computed. These three temperature distribution curves are redrawn in a graph in figures $4 a$ and $4 b$. The temperature difference between the two curves in figure $4 b$ is nearly constant at about $\Delta t_{\mathrm{e}}=65-70 \mathrm{~K}$. This is tho difference between the area coated with Enecoat and the uncoated surface. Numeric values for the temperature represent the so-called effective black body temperature.

\subsection{Low emissivity sun reflecting coating}

Sun reflecting coating materials are used in ambient temperature applications (undor $80^{\circ} \mathrm{C}$ ) such as walls, roofs, heat shields, etc., where thermal radiation is a dominant mechanism of heat transfer [4]. In the first step of the measuring process the $1 \mathrm{R}$ 
imaging equipment receives both the radiation emitted by the specimen and the sun radiation reflected from it (figure 5). In the second step, shielding the sample from the sunshine, the IR-imaging equipment receives only the radiation emitted by the differently heated coated and uncoated sides of the specimen. The very short time having been elapsed between the shielding and the measurement again allows the assumption that the effects of transient changes are negligible. The surface emissivity of the coating was compared with that of the specimen material.

In figure $A^{*}$ (colour photograph), on the thermogram there are two quadrangles marked for which temperature distribution was computed. Data for the coated left side histogram: $\max : 32.8^{\circ} \mathrm{C}, \min : 30.5^{\circ} \mathrm{C}$, avg:31.7 ${ }^{\circ} \mathrm{C}$, med: $31.8^{\circ} \mathrm{C}$, sdev: $0.4 \mathrm{~K}$, skew: $0.4 \mathrm{~K}$, ncal: 1794 pixels, fmax: 463 pixels and for uncoated side: avg: $41.0^{\circ} \mathrm{C}$. The temperature difference between the area coated with $P A C E$-coating [5] and the uncoated surface (approx.: 41-31.9 =9.1 K) shows that the PACE-coating directly decreases the IR-emissivity of the material.

Using the emissivity of different materials, several diagrams were calculated for the equilibrium wall temperature $\left(t_{\text {we }}\right)$ and heat gain of the surface of wall structure in function of different parameters (intensity of direct sunshine, environmental temperature, coefficient of heat transfer, thermal resistance of wall structure, etc.). In the following examples all the temperatures are real temperatures and were obtained by taking into account the emissivity of the individual materials.

\section{Halogen lamp}

Internal and superficial temperature distributions of a TCF 250 6A-type high pressure sodium-vapour lamp made by Tungsram were tested, helping to determine thermal fatigue, hence expected service life of the sodium-vapour lamp. One horizontal (a) and vertical (b) temperature curves across the sodium-vapour tube in the lamp can be seen in figure 6 .

\section{Efficiency of thermal insulation of steam turbines}

Comparative analysis has been made between thermal insulations of two turbines of the same type and service condition. The results may also help to repair thermal insulation. Histogram of LIMPET (British made) insulation: max: $197^{\circ} \mathrm{C}$, $\min$ : $30.5^{\circ} \mathrm{C}$, avg: $75.4^{\circ} \mathrm{C}$. Histogram of the Hungarian insulation: max: $157^{\circ} \mathrm{C}$, min: $32.5^{\circ} \mathrm{C}$, avg: $50.2 .{ }^{\circ} \mathrm{C}$

\section{Checking high-voltage transmission lines}

Checking $220 \mathrm{kV}$ high-voltage transmission lines from a helicopter demonstrated contact resistance defects. Histogram: max: $20.8^{\circ} \mathrm{C}, \min : 15.5^{\circ} \mathrm{C}$, avg: $17.1^{\circ} \mathrm{C}$ at $15.5^{\circ} \mathrm{C}$ ambient temperature. 


\section{Insulation defects of district heating}

Infrared pictures taken from heating pipelines hint to possible causes of heat losses. Typical insulation defects of heating pipelines can be discovered. Histogram: max: $20.8^{\circ} \mathrm{C}$, min: $15.5^{\circ} \mathrm{C}$, avg: $17.1^{\circ} \mathrm{C}$ at $15.5^{\circ} \mathrm{C}$ ambient temperature.

\section{Detection of leakage spots}

Leakage spots of gas pipelines may be pointed out in IR-images, thanks to the concomitant thermodynamical phenomena. Detection of leakage spots of a vacuum chamber were identified by means of images taken inside.

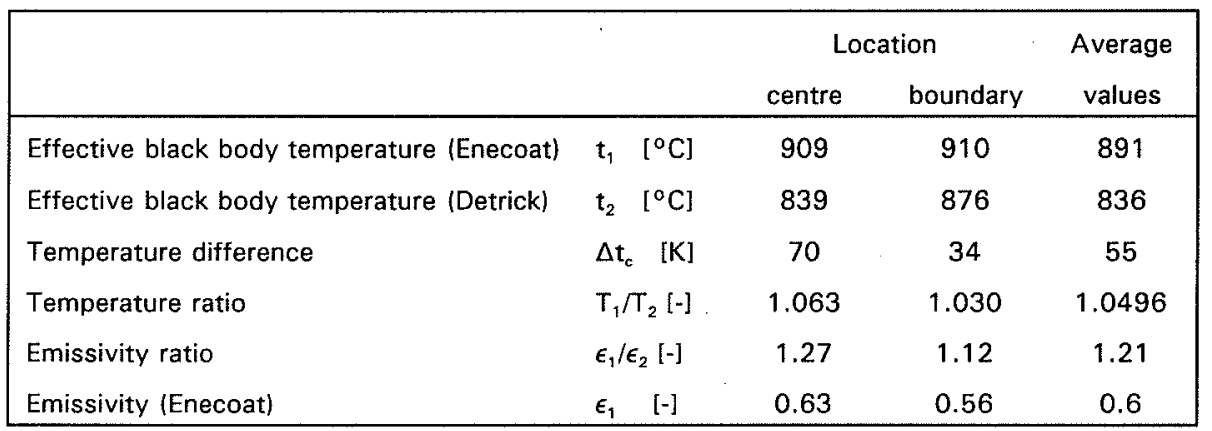

Table 1. - Enecoat emissivity $\epsilon_{1}$ at $960^{\circ} \mathrm{C}$

\section{REFERENCES}

[1'] BENKÖ (1.). - Energetical and other applications of thermogrammetric CAD (in Hungarian). Mérés és Automatika, 37, 1989, p. 69-73 and 99-102.

[2] BENKÖ (1.). - Industrial application and effects of Enecoat to increase surface emissivity. ENCONET Newsletter (UNDP/UNIDO project'Industrial energy conservation network'), 1991, p.3-8. and Mérés és Automatika, 39, 1991, p. 67-71.

[3] BENKÖ (I.). - High emissivity coating for energy conservation in furnaces. Proceedings of the $2^{\text {nd }}$ International Heat and Mass Transfer Conference. Minsk, 1992. Vol. 2. Radiative and combined heat transfer, p. 35-42.

[4] BENKÖ (1.). - Applications of low emissivity coatings in the thermo-technique of buildings. Proceedings of Interklima '91. Zagreb, 1991, p. 154-155.

[5] BENKO (1.). - Examination of low emissivity coatings by infrared imagery. Proceedings of the Workshop on Advanced Infrared Technology and Applications. (I.R.O.E. del C.N.R) Florence, 1992, p. 32.

[6] BENKÓ (1.). - Energy conservation through increased emissivity in furnaces. Periodica Politechnica, Budapest. Ser. Mech. Eng., 55, 1992, p. 1421-1433. 


\section{http://dx.doi.org/10.21611/qirt.1992.054}

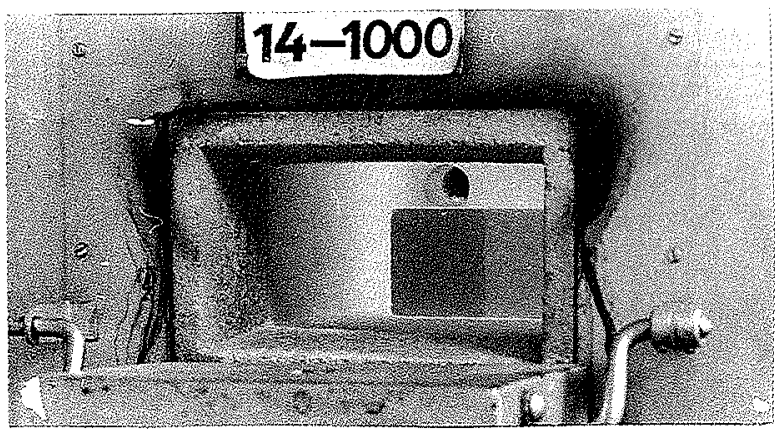

Fig.1. - Examining the effects of Enecoat. One of the samples in the furnace.
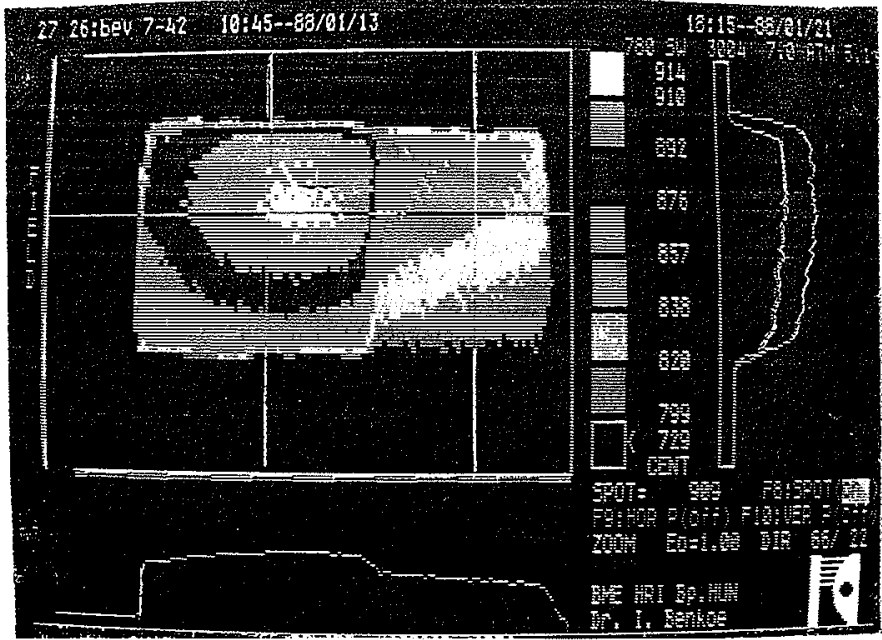

Fig. 2. - In the IR-thermogram the two temperature curves on the right show that Enecoat directly increases the infrared emissivity of the Detrick ceramic fibre material

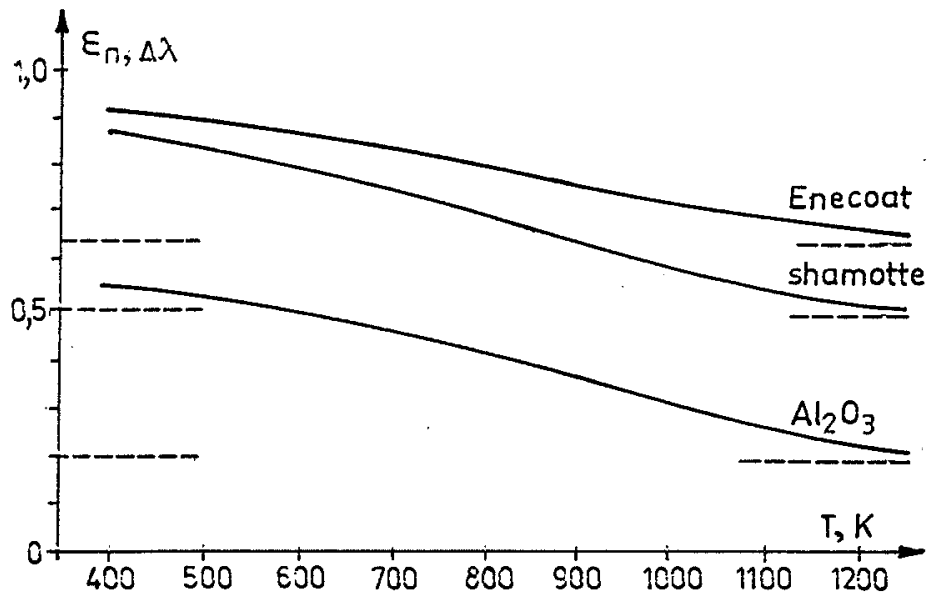

Fig.3. - Spectral normal emissivity of Enecoat, chamotte and ceramic fibre $\left(\mathrm{Al}_{2} \mathrm{O}_{3}\right)$ versus material surface temperature 
http://dx.doi.org/10.21611/qirt.1992.054

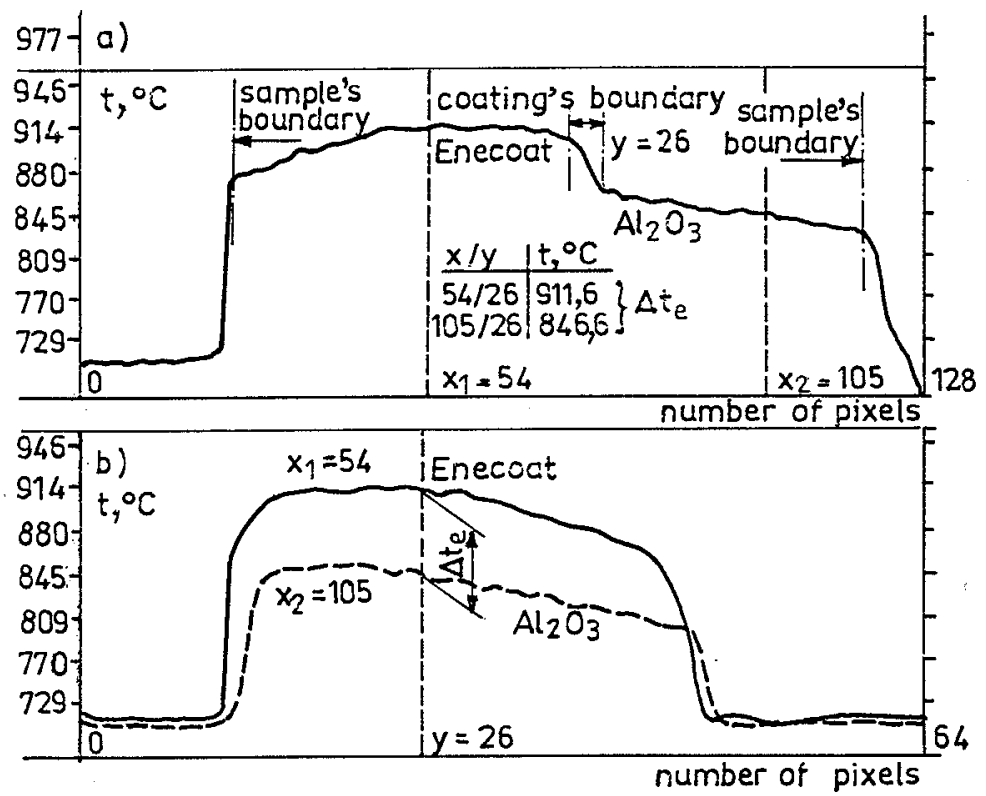

Fig.4a. - Temperature curve presented in the bottom part of Fig.2.

Fig.4b. - Temperature curves presented in the right side of Fig. 2 .

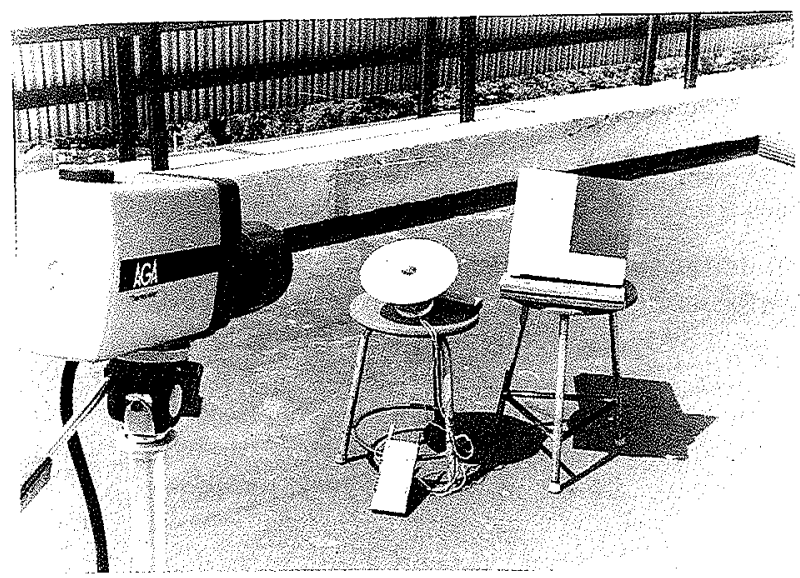

Fig.5. - Measurement rig for examining the effects of selective sun reflecting coating 
http://dx.doi.org/10.21611/qirt.1992.054

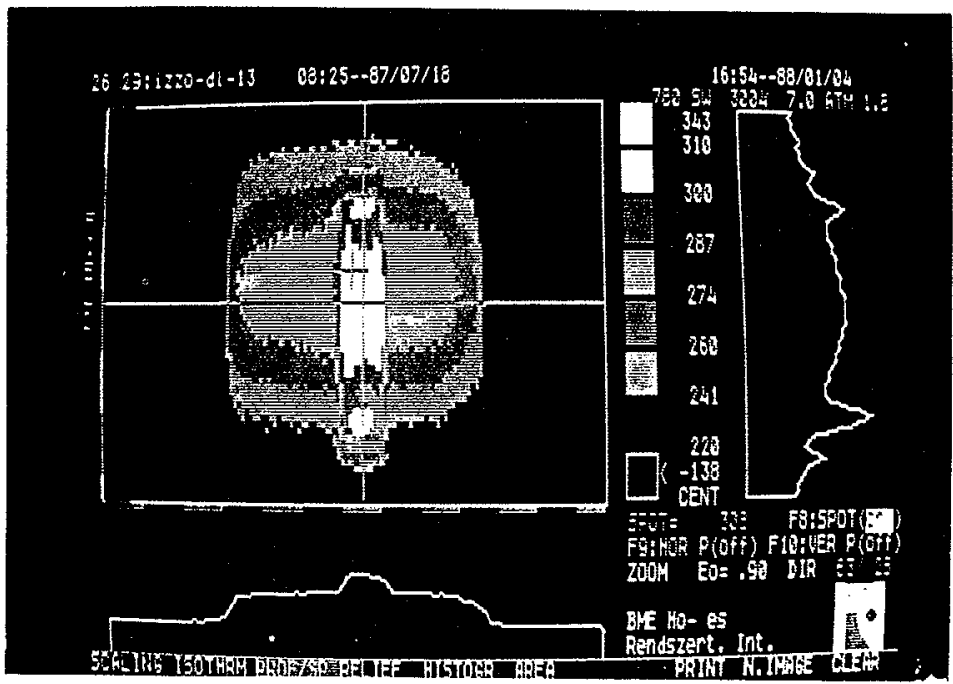

Fig.6 - IR-thermogram of a sodium-vapour tube in the lamp and profile thermograms across the tube 
http://dx.doi.org/10.21611/qirt.1992.054 